\title{
OS LUGARES FORMAIS DE CULTURA E LAZER DO MUNICÍPIO DE FEIRA DE SANTANA - BA
}

\author{
Willian Falcão Lopes'; Maria Cleonice Barbosa Braga ${ }^{2}$ \\ 1. Bolsista Probic, Graduando em Bacharelado em Geografia, Universidade Estadual de Feira de Santana, e- \\ mail: willianf.1@hotmail.com \\ 2. Orientadora, Departamento de Educação, Universidade Estadual de Feira de Santana, e-mail: \\ nicebraga08@gmail.com
}

PALAVRAS-CHAVE: Cultura; lazer, lugares formais.

\section{INTRODUÇÃO}

Ser professor no atual cenário de desigualdades sociais e econômicas em que se encontra o Brasil perpassa atualmente por diversas problemáticas e uma delas é o entendimento do processo de globalização, ao qual junto ao modelo econômico capitalista, neoliberal, transcorrem uma ideia de que o mundo está globalizado/homogêneo, esquecendo-se de que esse é um processo desigual e combinado, que muitas vezes é propagado como fábula. (SANTOS, 2000).

É diante desse contexto que, muitos dos professores de Geografia, movidos pela própria mercadorização da educação, desenvolvem práticas uniformes, prontas e acabadas, esquecendo-se de que o aluno é um sujeito ativo nas relações de ensinoaprendizagem e que o mesmo é dotado de vivências e culturas, e que estas últimas devem ser trabalhadas para uma aprendizagem mais significativa e contextualizada dos conteúdos geográficos.

Diante disso, o seguinte trabalho teve por objetivo geral identificar e analisar os lugares formais de cultura e lazer do município de Feira de Santana - BA. Já como objetivos específicos identificar os lugares formais de cultura e lazer do município de Feira de Santana; desconstruir a ideia de que no município de Feira de Santana inexiste lugares de cultura e lazer; identificar e analisar o perfil socioeconômico e etário dos visitantes dos lugares pesquisados; mapear os lugares formais de produção de cultura e lazer do presente município; compreender os significados dos lugares formais de cultura e lazer para a população feirense.

Dentre os principais motivos para realização dessa investigação estão: o objetivo do projeto "Lugar, formação docente e elaboração de material didático-pedagógico sobre Feira de Santana/BA" e a necessidade de aprofundamento e continuidade de minha investigação de Iniciação Científica, anterior, bolsa Fapesb 2013, intitulada "As aulas dos estagiários de Geografia da UEFS: concepções e práticas".

Atualmente o projeto "lugar" vive um momento de identificação de alguns dos aspectos físicos e sociais do município de Feira de Santana - BA. Diante disso, de acordo com o objetivo específico desse projeto "elaborar materiais didático-pedagógicos e atividades que sirvam de apoio para o estudo do lugar Feira de Santana nas escolas" foi pensada a seguinte questão de pesquisa: Quais são os lugares formais de produção de cultura e lazer do município de Feira de Santana - BA? Quais os significados desses lugares para a população feirense? A partir desse estudo, posteriormente visa-se, em extensão, o desenvolvimento de materiais didáticos-pedagógicos sobre essa temática.

Em investigação anterior, (LOPES E BRAGA, 2014) identificou-se que mesmo sendo bastante discutido na universidade pelos professores da subárea de educação a importância do trabalho com os saberes culturais e vivencias dos estudantes, na prática os estagiários continuam a dar aula e a transmitir os conteúdos dos livros didáticos ou de outras fontes. Diante disso, essa investigação possibilitará o reconhecimento dos lugares formais de cultura e lazer desse município, para o possível trabalho com essas informações em sala de aula com os estudantes. Além de auxiliar na desconstrução da ideia de que no município de Feira de Santana inexiste esses lugares.

Essa investigação foi um estudo de caso com os frequentadores dos lugares formais, lugares de produção e de construção de relações de identidade e de afetividades que são reconhecidos de maneira geral pela comunidade local, pelos sujeitos do município de Feira de Santana, como pontos específicos para o desenvolvimento de atividades de cultura e lazer. 


\section{METODOLOGIA}

Para o alcance dos objetivos propostos por esse trabalho a abordagem que foi adotada é a qualitativa que, de acordo com André (1992), têm caráter exploratório, isto é, estimulam os sujeitos participantes (pesquisador e pesquisados) a refletirem livremente sobre a temática investigada. Além de que o pesquisador busca o questionamento da suposta neutralidade científica à medida em que ele desenvolve considerações e compreensões a partir dos dados construídos no exercício do cotidiano da pesquisa, ao invés de apenas comprovar hipóteses e modelos pré-estabelecidos em busca da existência de uma verdade única.

Nesse contexto, o método qualitativo utilizado foi o estudo de caso que, para Godoy (1995), tem como finalidade a análise aprofundada de uma unidade social. Esse tipo de método é específico de pesquisa de campo na qual se adota um olhar exploratório, descritivo e analítico, compreendendo que se faz necessário ressaltar as várias dimensões em que se apresenta tanto o fenômeno como o ambiente localizado.

Na primeira fase ocorreram levantamentos, seleção e análise do material bibliográfico em bibliotecas e em fontes virtuais, que forneceram subsídios teóricos para as outras etapas da pesquisa.

$\mathrm{Na}$ segunda fase da investigação foram delimitados 6 lugares formais (Mercado de Arte Popular, Centro Universitário de Cultura e Artes - CUCA, Centro Cultural Amélio Amorim, Praça de Skate e de Alimentação do Centro Comercial, Parque da Cidade Frei José Monteiro Sobrinho e Parque da Lagoa Radialista Erivaldo Cerqueira), lugares reconhecidos pelos sujeitos do município de Feira de Santana como pontos de produção de cultura e lazer.

Nos já referidos lugares foram feitas entrevistas semiestruturadas com 135 sujeitos colaboradores. Essas entrevistas visavam identificar o perfil socioeconômico, etário e as relações de identidade entre os visitantes e os lugares investigados. As entrevistas foram descritas de forma analítica para uma melhor compreensão dos dados.

Para Ludke e André (1986), a entrevista é um meio utilizado em pesquisas de abordagem qualitativa, pois favorece um diálogo entre investigador e entrevistado, valorizando as subjetividades dos sujeitos pesquisados. Sobre a entrevista semiestruturada é um diálogo direcionado para um determinado tema, podendo ser adaptado sem rigidez ou predeterminações.

$\mathrm{Na}$ terceira fase foi feito o mapeamento geográfico e construção de fotografias dos lugares trabalhados nessa investigação. Contudo, diante da limitação imposta quanto ao número de páginas para o desenvolvimento do resumo expandido ambos não serão apresentados no presente trabalho.

Por fim, na quarta fase foi feita a análise e interpretação dos dados a luz dos teóricos que subsidiaram a investigação.

\section{ANÁLISE E DISCUSSÃO DOS RESULTADOS}

Nesse item, foram apresentados os lugares formais de cultura e lazer do município de Feira de Santana; bem como a desconstrução da ideia de que inexistem esses lugares em Feira; sendo discutido o perfil socioeconômico e etário dos visitantes destes lugares pesquisados; além disso será feito o diálogo dos significados dos lugares formais de cultura e lazer para a população feirense.

Para identificação dos lugares de produção de cultura e lazer foram feitas incialmente entrevistas com 20 sujeitos aos quais lhe foi feita a seguinte indagação: Em quais lugares de Feira de Santana é possível ter acesso a atividades voltadas a produção da cultura e Lazer? Com suas respostas e diante as orientações foram demarcados 6 locais principais de produção de cultura e lazer, já apontados na metodologia.

Pode-se dizer que a maioria dos lugares investigados se encontra no centro ou estreitamente próxima a ele, localidade que conta com os maiores fluxos de transporte rodoviário e urbano do município. Já a minoria encontra-se em localidades de extremidades, geograficamente zonas marginais em contrapartida a cidade, com menor acesso pelos meios de transportes públicos disponíveis pelo município. 
A grande maioria dos teatros, dos espaços de apresentações artísticas e museus encontram-se no centro, local de fácil acesso para os sujeitos que ali moram ou que moram nas suas proximidades. Estes são locais bastantes frequentados por sujeitos de maiores níveis de escolaridade e de poder aquisitivo, que neles buscam uma dada/específica Arte, Cultura e Lazer. Já o Mercado de Arte, esse mantém sua localização no Centro, como um espaço que lhe é extremante oportuno. Cabe ressaltar que é bastante visitado por turistas de outros municípios, o que lhe facilita uma mais rápida reprodução de capital, visto que os materiais e atividades lá produzidos e comercializados são atingidos, na maioria dos casos, por públicos imigrantes ou pela maioria da população feirense com menores índice de renda e escolaridade. Os parques, encontram-se em zonas distantes e com pouco acesso, pelas vias de transporte público, ou zonas geograficamente atingidas por população de menor poder aquisitivo.

Sobre o perfil etário dos sujeitos investigados, de maneira geral, pode-se dizer que a maioria se encontra entre a faixa dos 18 aos 29 anos com 40\%, seguida pela dos 13 aos 17 anos com $21 \%$, sendo maioria de jovens seguidos de adolescentes. Já o menor público encontrado nos espaços foi o superior aos 50 anos com $7 \%$ de representação.

Cabe ressaltar, que para identificação da identidade étnica dos sujeitos partimos do ponto que este devia se autodeclarar como ele se enxergava e era visto pelos sujeitos que the rodeavam, o que nos levou ao entendimento de que muitos dos sujeitos ainda confundem cor/es com grupos étnicos. Além de que, muitas das cor/es e grupos apresentados eram singulares as categorias padrões, feitas pelos órgãos responsáveis pelos sensos, como cor moreno e etnia caramelo. Diálogos mais aprofundados com os sujeitos tentamos categorizar tais novidades a grupos específicos.

Dentre os principais motivos para a compreenção de que inexistem espaços de cultura e Lazer em Feira de Santana são apontados a falta de opções, $20 \%$, de diversificação desses espaços. Diante da análise dos dados, muitas vezes isso é associado a falta de incentivo governamental, 13,3\%, para a contrução de lugares voltados ao desenvolvimento de atividades culturais e de lazer.

Em diálogos com os sujeitos entrevistados chegou-se ao entendimento que não há uma divulgação, 6,7\%, não é do interesse por parte dos representantes do múnicipio ou do foco de reprodução do capital da cidade que esta seja vista como um espaço de lazer ou de promoção/produção de culturas, a final, um dos slogans de Feira é "cidade Trabalho" não cidade culturas ou ainda cidade lazer, e muitas vezes essa tem deixado a desejar quanto aos espaço de ócio, de fulga de rotina, de diversão ou recreação para a massa populacional cansada, exausta pela dinâmica/carga-horaria semanal de trabalho.

O entendimento alcançado é que Feira tem sim, espaços de cultura e lazer. Contudo, não são tão diversificados quanto os apresentados pelo município próximo, Salvador, e isso muitas vezes tem levado a grande parte dos sujeitos a buscarem essa maior variedade de atividades recreativas e culturais fora de Feira. De fato, pode-se sim ser mais investido na construção de lugares de cultura e lazer, seria até um meio de promover atividades que potencializam a cidade e sua cultura, mas será que estes serão tão apreciados e frequentados quanto aos do município próximo? Pois ao que me parece a "grama do vizinho sempre é mais verde" e mesmo com a ampliação dessas atividades o município não teria como promover a mesma diversidade que a capital oferta.

Pode-se apontar que o principal fator de atratividade dos lugares feirenses é a possibilidade de diversão, entretenimento ou ainda a fuga da rotina; $42 \%$, dos que apontam essa categoria mantêm uma frequência cotidiana nesses lugares, a fim de terem um espaço de relaxamento, de descontração ou ainda de fuga da rotina semanal de trabalho. Sendo esses lugares potencializadores de construções de levezas, alegrias e relaxamentos diante, muitas vezes, de um contexto pesado de atividades trabalhistas.

Ademais, $18 \%$ apontam como principal fator de identidade com esses lugares a diversidade de fazeres artísticos e culturais por ele proporcionados. $2 \%$ apontam a vivência que ali é proporcionada. $6 \%$, apontou que a sua relação deve-se diante da proximidade com o lugar. Há ainda, os que apontaram a necessidade de valorização do lugar. 7\%, apontou que deve-se a partir de relações de consumo. 3\% dos sujeitos, utilizam os espaços para praticarem exercícios, atividades esportivas. Por fim, 11\%, apontam frequentarem esses espaços a partir de uma necessidade humana de socialização e de interação. 


\section{CONSIDERAÇÕES FINAIS}

Dessa forma, é possível afirmar que essa investigação buscou analisar os lugares formais de cultura e lazer do município de Feira de Santana - BA, bem como, desconstruir a ideia de que inexistem lugares de cultura e lazer em Feira e identificar como se desenvolvem as relações de identidade dos sujeitos com esses lugares.

Pode-se dizer que em Feira de Santana existem sim lugares de produção de cultura e lazer e que esses são de conhecimento da população local. Contudo, não são tão diversificados quanto os apresentados pelo município próximo, Salvador, e isso muitas vezes tem levado grande parte dos sujeitos a buscarem essa maior variedade de atividades recreativas e culturais fora de Feira.

Os principais lugares apontados pela população feirense foram o Mercado de Arte Popular, Centro Universitário de Cultura e Artes - CUCA, Centro Cultural Amélio Amorim, Praça de Skate e de Alimentação do Centro Comercial, Parque da Cidade Frei José Monteiro Sobrinho e Parque da Lagoa Radialista Erivaldo Cerqueira, lugares mais reconhecidos pelos sujeitos do município de Feira de Santana (BA) como pontos de produção de cultura e lazer.

Por fim, cabe ressaltar, que as relações identidade, afetividade e de vivências dos sujeitos com os lugares deve-se através da busca de um meio de sustento, de diversidade de fazeres atísticos, culturais, proximidade com a habitação, valorização do lugar, diversão entretenimento, fuga de rotina, consumo, exercitação ou ainda socialização e interação.

\section{REFERÊNCIAS}

ANDRE, M. E. D. A. Cotidiano escolar e práticas Sócio-Pedagógicas. Em Aberto, Brasília, n. 53, p. 29-38, 1992.

GODOY, A. S.. Pesquisa qualitativa: tipos fundamentais. Revista de Administração de Empresas, São Paulo, v. 35, n. 3, p. 20-29, mai./jun. 1995.

LOPES, W. F. ; BRAGA, M. C. B. . As concepções teórico-metodológicas que fundamentam as aulas dos estagiários de Geografia da UEFS. In: $4^{\circ}$ Encontro Regional de Ensino de Geografia - Campinas, 2014, Campinas. Formação de professores de Geografia: políticas e práticas curriculares. Campinas: Associação de Geógrafos do Brasil - Sessão Campinas; IG/UNICAMP, 2014. v. IV. p. 214-228.

LUDKE, M.; ANDRÉ, M. E. D. A.. Pesquisa em educação: Abordagens qualitativas. São Paulo: EPU, 1986.

SANTOS, M. Por uma outra globalização: do pensamento único a consciência universal. 3. ed. Rio de Janeiro: Record Editora, 2000. 